\title{
Exploration of wheat and pathogen transcriptomes during tan spot infection
}

\author{
Paula Moolhuijzen ${ }^{*}$ (D, Pao Theen See and Caroline S. Moffat
}

\begin{abstract}
Objectives: The fungus Pyrenophora tritici-repentis is the causal agent of tan spot, a major disease of wheat (Triticum aestivum). Here, we used RNA sequencing to generate transcriptional datasets for both the host and pathogen during infection and during in vitro pathogen growth stages.

Data description: To capture gene expression during wheat infection with the P. tritici-repentis isolate M4, RNA datasets were generated for wheat inoculated with P. tritici-repentis (infection) and a mock (control) at 3 and 4 days postinfection, when scorable leaf disease symptoms manifest. The P. tritici-repentis isolate M4 was also RNA sequenced to capture gene expression in vitro at two different growth stages: 7-day old vegetative mycelia and 9-day old sporulating mycelia, to coincide with a latent growth stage and early sporulation respectively. In total, 6 RNA datasets are available to aid in the validation of predicted genes of $P$. tritici-repentis and wheat. The datasets generated offer an insight into the transcriptomic profile of the host-pathogen interaction and can be used to investigate the expression of a subset of transcripts or targeted genes prior to designing cost-intensive RNA sequencing experiments, that would be best further explored with replication and a time series analysis.
\end{abstract}

Keywords: Pyrenophora tritici-repentis, Transcriptome, ToxA, RNA-seq, Tan spot, Triticum aestivum, Wheat, Yellow spot

\section{Objective}

The necrotrophic fungal pathogen Pyrenophora triticirepentis causes tan spot disease of wheat (Triticum aestivum). Tan spot is an economically significant leaf disease, which has a major impact on the wheat industry worldwide. Here, we present exploratory RNA sequence data sets with the following aims: (1) to investigate in planta gene expression of both the host and pathogen during wheat tan spot infection by $P$. tritici-repentis, (2) to investigate in vitro $P$. tritici-repentis gene expression during vegetative and sporulating growth stages, and (3) to provide RNA sequencing for bioinformatics support of gene predictions in P. tritici-repentis [1] and wheat.

\section{Data description}

In total, six RNA libraries were Illumina HiSeq sequenced to yield 24 and 25 million read pairs respectively for 3 and 4 days post-infection with $P$. tritici-repentis, 28 and 23

\footnotetext{
*Correspondence: paula.moolhuijzen@curtin.edu.au Centre for Crop Disease and Management, Curtin University, Perth, WA, Australia
}

million read pairs respectively for 3 and 4 days post-inoculation of control wheat, and 23 and 26 million read pairs for 7-day old vegetative fungal mycelia and 9-day old sporulating mycelia respectively (Data file 1) (Table 1). The time points were chosen to maximise the appearance of early disease symptoms in planta and capture a latent growth and sporulating growth phase in vitro.

To determine host gene expression during P. triticirepentis infection, datasets from infected and noninfected leaf samples were individually aligned to the Chinese Spring wheat genome (IWGS V1.0) [2]. Over half of the reads for each dataset mapped to the wheat genome (Data file 1). A total of 33,449 genes (24\%) of the 137,056 high-confidence wheat reference genes were detected in both the control and infected groups (Data file 2).

For $P$. tritici-repentis expression during host infection, datasets from 3 and 4 days post-infection were also individually aligned to the $P$. tritici-repentis genome of isolate M4 [1]. Only $0.4-0.6 \%$ of the sample reads mapped to the genome (Data file 1). A total of 9101 and 9824 transcripts 
Table 1 Overview of data files/data sets

\begin{tabular}{|c|c|c|c|}
\hline Label & Name data set & File types (file extension) & Data repository and identifier \\
\hline Supplementary file 1 & Methodology description & Word document (.docx) & https://doi.org/10.6084/m9.figshare.7019843 \\
\hline Data file 1 & Table of RNA sample collection and statistics & Spreadsheet (.xIsx) & https://doi.org/10.6084/m9.figshare.7019843 \\
\hline Data file 2 & $\begin{array}{l}\text { Wheat gene expression } 3 \text { and } 4 \text { days post- } \\
\text { infection }\end{array}$ & Spreadsheet (.x|sx) & https://doi.org/10.6084/m9.figshare.7019843 \\
\hline Data file 3 & $\begin{array}{c}\text { Pyrenophora tritici-repentis gene expression in } \\
\text { planta at days } 3 \text { and } 4 \text { days post-infection }\end{array}$ & Spreadsheet (.x|sx) & https://doi.org/10.6084/m9.figshare.7019843 \\
\hline Data file 4 & $\begin{array}{l}\text { Pyrenophora tritici-repentis (isolate M4) gene } \\
\text { expression in vitro of vegetative and sporulat- } \\
\text { ing mycelia }\end{array}$ & Spreadsheet (.x|sx) & https://doi.org/10.6084/m9.figshare.7019843 \\
\hline Data set 5 & $\begin{array}{l}\text { Sample } \mathrm{C} 1,3 \text { days post-control inoculation in } \\
\text { planta }\end{array}$ & Fastq (fastq.gz) & $\begin{array}{l}\text { European Nucleotide Archive (ENA) Run } \\
\text { accession ERR2822756 (https://www.ebi. } \\
\text { ac.uk/ena/data/view/ERR2822756) }\end{array}$ \\
\hline Data set 6 & $\begin{array}{l}\text { Sample } \mathrm{C} 2,4 \text { days post-control inoculation in } \\
\text { planta }\end{array}$ & Fastq (fastq.gz) & $\begin{array}{l}\text { European Nucleotide Archive (ENA) Run } \\
\text { accession ERR2822757 (https://www.ebi. } \\
\text { ac.uk/ena/data/view/ERR2822757) }\end{array}$ \\
\hline Data set 7 & Sample M1, 7-day in vitro vegetative mycelia & Fastq (fastq.gz) & $\begin{array}{l}\text { European Nucleotide Archive (ENA) Run } \\
\text { accession ERR2822758 (https://www.ebi. } \\
\text { ac.uk/ena/data/view/ERR2822758) }\end{array}$ \\
\hline Data set 8 & Sample M2, 9-day in vitro sporulating mycelia & Fastq (fastq.gz) & $\begin{array}{l}\text { European Nucleotide Archive (ENA) Run } \\
\text { accession ERR2822759 (https://www.ebi. } \\
\text { ac.uk/ena/data/view/ERR2822759) }\end{array}$ \\
\hline Data set 9 & $\begin{array}{l}\text { Sample P1, } 3 \text { DPI P. tritici-repentis infection in } \\
\text { planta }\end{array}$ & Fastq (fastq.gz) & $\begin{array}{l}\text { European Nucleotide Archive (ENA) Run } \\
\text { accession ERR2822760 (https://www.ebi. } \\
\text { ac.uk/ena/data/view/ERR2822760) }\end{array}$ \\
\hline Data set 10 & $\begin{array}{l}\text { Sample P2, } 4 \text { DPI P. tritici-repentis infection in } \\
\text { planta }\end{array}$ & Fastq (fastq.gz) & $\begin{array}{l}\text { European Nucleotide Archive (ENA) Run } \\
\text { accession ERR2822761 (https://www.ebi. } \\
\text { ac.uk/ena/data/view/ERR2822761) }\end{array}$ \\
\hline
\end{tabular}

were detected at 3 and 4 days post-infection respectively (Data file 3).

To profile $P$. tritici-repentis genes expressed at different mycelia growth stages, the in vitro vegetative and sporulating datasets were individually aligned to the M4 genome [1] with approximately half of the reads in concordant alignment (Data file 1). A total of 10,933 M4 transcripts were expressed in vitro and of these 8548 transcripts were found expressed in both vegetative and sporulating mycelia (Data file 4).

\section{Methodology}

\section{Plant and fungal material}

The fully extended leaves of the 2-week-old susceptible wheat (Triticum aestivum) variety Machete were inoculated with the $P$. tritici-repentis race $1 \mathrm{M} 4$ isolate or a mock control solution [3]. Infected and control leaves were collected at 3 and 4 days post-inoculation (DPI). In vitro M4 samples of vegetative mycelia and sporulating mycelia grown on V8PDA agar [3] were harvested at 7 days and 9 days respectively. All samples were snap frozen in liquid nitrogen immediately after harvest, and stored at $-80^{\circ} \mathrm{C}$ prior to RNA extraction.

\section{RNA extraction and sequencing}

RNA was extracted using TRIzol Reagent (Thermo Fisher Scientific, USA), further purified using Zymo-Spin columns (Zymo Research, USA) as per the manufacturer's guidelines prior to $\mathrm{LiCl}$ precipitation. RNA samples were pooled from 3 biological replicates. Isolated RNA was ribo-depleted and sequenced as un-stranded, $100 \mathrm{bp}$ pair-end (PE) reads on an Illumina HiSeq2000 machine. A total of $30.6 \mathrm{~Gb}$ of raw sequence of 6 libraries was obtained. Further method details can be found in Supplementary file 1 .

\section{Sequence analysis}

Reads were quality checked with FASTQC [4] and trimmed using TrimmomaticPE V0.32 [5]. The trimmed reads were aligned to the $P$. tritici-repentis M4 reference genome (NCBI GenBank accession NQIK00000000.1) [1] and wheat Chinese Spring genome IWGS V1.0 [2] using Bowtie2/TopHat2 version 2.0.9 [6, 7]. Expression analysis was conducted with the Cufflinks package guided by the reference genes for M4 and high confidence genes in wheat [8]. 


\section{Limitations}

The data sets generated were pooled from three biological RNA samples and therefore have no replicates for differential expression studies. The downloadable sequence data is stored raw and requires quality filtering before use.

\author{
Abbreviations \\ DPI: days post-inoculation; RNA-seq: RNA sequencing; PE: paired-end.
}

\section{Authors' contributions}

PM conducted the bioinformatics analysis and wrote the draft manuscript. PTS and CM conducted the molecular analysis. CM and PTS contributed to reviewing and editing this manuscript. CM led the project conceptualization. All authors agree to the publication policies of BMC Data Notes. All authors read and approved the final manuscript.

\begin{abstract}
Acknowledgements
We thank the Australian Government National Collaborative Research Infrastructure Strategy (NCRIS) for providing access to Pawsey Supercomputing under a National Computational Merit Allocation Scheme (NCMAS), Nectar Research/Pawsey Nimbus Cloud resources and the Australian Wheat Pathogens Consortium, BioPlatforms Australia (BPA).
\end{abstract}

\section{Competing interests}

The authors declare that they have no competing interests.

\section{Availability of data materials}

The datasets generated during and/or analysed during the current study are available in the figshare repository [9]. All RNA-seq read data is available through European Nucleotide Archive (ENA) under study primary accession PRJEB29046 or secondary accession ERP111314. The RNA-seq read data can also be accessed from [10]. Direct links to data sets are: Sample M1, 7 day in vitro vegetative mycelia (102.100.100.14350); Sample M2, 9 day in vitro sporulating mycelia (102.100.100.14351); Sample P1, 3 DPI P. tritici-repentis infection in planta (102.100.100.14355); Sample P2, 4 DPI P. tritici-repentis infection in planta (102.100.100.14357); Sample C1, 3 days post-control inoculation in planta (102.100.100.14354); Sample C2, 4 days post-control inoculation in planta (102.100.100.14356).

\section{Consent for publication}

Not applicable.

\section{Ethics approval and consent to participate}

Not applicable.

\section{Funding}

The RNA sequencing was generously supported through BioPlatforms Australia and funded by the Australian Government National Collaborative
Research Infrastructure Strategy and Education Investment Fund Super Science Initiative. The analysis, data interpretation and writing of the manuscript were generously funded through the Grains and Research Development Corporation (project code CUR0023).

\section{Publisher's Note}

Springer Nature remains neutral with regard to jurisdictional claims in published maps and institutional affiliations.

Received: 27 September 2018 Accepted: 6 December 2018

Published online: 19 December 2018

\section{References}

1. Moolhuijzen P, See PT, Hane JK, Shi G, Liu Z, Oliver RP, et al. Comparative genomics of the wheat fungal pathogen Pyrenophora tritici-repentis reveals chromosomal variations and genome plasticity. BMC Genomics. 2018;19(1):279. https://doi.org/10.1186/s12864-018-4680-3.

2. International Wheat Genome Sequencing C. A chromosome-based draft sequence of the hexaploid bread wheat (Triticum aestivum) genome. Science. 2014;345(6194):1251788. https://doi.org/10.1126/science.1251788.

3. Moffat CS, See PT, Oliver RP. Generation of a ToxA knockout strain of the wheat tan spot pathogen Pyrenophora tritici-repentis. Mol Plant Pathol. 2014;15(9):918-26. https://doi.org/10.1111/mpp.12154.

4. Andrews S. FastQC 2011; 2016. http://www.bioinformatics.babraham. ac.uk/projects/fastqc/. Accessed 2016.

5. Bolger AM, Lohse M, Usadel B. Trimmomatic: a flexible trimmer for Illumina sequence data. Bioinformatics. 2014;30(15):2114-20. https://doi. org/10.1093/bioinformatics/btu170.

6. Langdon WB. Performance of genetic programming optimised Bowtie2 on genome comparison and analytic testing (GCAT) benchmarks. BioData Min. 2015;8(1):1. https://doi.org/10.1186/s13040-014-0034-0.

7. Kim D, Salzberg SL. TopHat-Fusion: an algorithm for discovery of novel fusion transcripts. Genome Biol. 2011;12(8):R72. https://doi.org/10.1186/ gb-2011-12-8-r72.

8. Trapnell C, Roberts A, Goff L, Pertea G, Kim D, Kelley DR, et al. Differential gene and transcript expression analysis of RNA-seq experiments with TopHat and Cufflinks. Nat Protoc. 2012;7(3):562-78. https://doi. org/10.1038/nprot.2012.016.

9. Moolhuijzen P, See PT, Moffat CS. Pyrenophora tritici-repentis (isolate M4) RNA-seq analysis of in vitro samples and in planta samples during wheat tan spot infection figshare; 2018. https://doi.org/10.6084/m9.figsh are.7019843.

10. Wheat pathogen transcript. National Research Infrastructure for Australia; 2013. https://data.bioplatforms.com/bpa/wheat_pathogens_transcript/ samples. Accessed 2015.

\footnotetext{
Ready to submit your research? Choose BMC and benefit from:

- fast, convenient online submission

- thorough peer review by experienced researchers in your field

- rapid publication on acceptance

- support for research data, including large and complex data types

- gold Open Access which fosters wider collaboration and increased citations

- maximum visibility for your research: over $100 \mathrm{M}$ website views per year
}

At BMC, research is always in progress.

Learn more biomedcentral.com/submissions 